\title{
Psychometric properties of the COVID-19 associated PTSD-Scale
}

\author{
Prof. Dr. Samer Jamil Rudwan
}

University of Nizwa, Sultanate of Oman

Doi:10.19044/esj.2021.v17n10p36

Submitted: 30 January 2021

Accepted: 10 March 2021

Published: 31 March 2021
Copyright 2021 Author(s)

Under Creative Commons BY-NC-ND

4.0 OPEN ACCESS

Cite As:

Rudwan S.J. (2021). Psychometric properties of the COVID-19 associated PTSD-Scale. European Scientific Journal, ESJ, 17(10), 36. https://doi.org/10.19044/esj.2021.v17n10p36

\section{Abstract}

This study aimed to create a scale to measure post-traumatic stress disorder (PTSD) symptoms related to the COVID 19 crisis. Based on the available studies, the Davidson PTSD scale dimensions were used in this online survey. Accordingly, a new scale was designed based on the clinical characteristics of the symptoms of the PTSD, so questions revolved around the possible psychological PTSD symptoms associated with COVID 19. Descriptive approach was used. The study involved 423 participants from the Sultanate of Oman, of whom, 219 were male and 204 were female. Statistical analyses of the scale were conducted using reliability, criterion-related validity, as well as exploratory and confirmatory factor analysis. The factor analysis revealed three factors to which 15 items of 17 items were loaded that reflect the clinical features of PTSD symptoms. Overall, the scale showed good internal consistency and stability, with relatively good correlations between the items within the factors. The analysis of the confirmation factors led to model fit validation with 14 items, with the results showing a high degree of conformity. Accordingly, the results were discussed, and further studies suggested to further verify and confirm the scale validity.

Keywords: COVID 19, PTSD, mental health, exploratory factor analysis, confirmatory factor analysis 


\section{Introduction}

\section{The theoretical framework and background of the study}

With the increasing spread of psychological problems and disorders as a result of the corona crisis, it has become necessary to provide suitable diagnostic tools required by psychologists and doctors from various disciplines as well as by people working in the field of crisis intervention to help those affected and to make appropriate decisions.

In most countries, medical institutions face many difficulties and psychological stress when dealing with emergencies. The same applies to basic medical and psychological care and psychological support for people infected with coronavirus and their families as well as those who have recovered from the disease. Furthermore, psychological pressures faced by medical workers, including doctors, nurses, assistants, and clerks, have resulted in symptoms of multiple mental disorders, such as anxiety, depression, obsessive-compulsive disorder, as well as symptoms of primary and secondary PTSD. An analysis of 2,144 calls made through the mental health hotline, conducted by the Wuhan Mental Health Center, found that $70 \%$ of the hotline users were the general public in the period from February 4 to 20, 2020, with $2.2 \%$ of medical workers calling the hotline. In total, $19.5 \%$ suffered from various mental disorders was $19.5 \%$ and the percentage of other employees was $8.3 \%$ (Sanwang, Win, Dong, Bin\& Cui, 2020).

The spread of the coronavirus has increased the risk of developing mental disorders in patients with a predisposition to the disorder or worsening symptoms in patients with original mental disorders. Some disorders are also directly related to corona infection, others may be related to behavioral warnings regarding the corona, including those related to long imprisonment, homestays, and lack of social activities.

Several studies have shown the prevalence of mental disorders among health workers and general population, for example, in China and Italy, varies, with anxiety symptoms in 12 to $20 \%$, depression between 14 to $20 \%$, sleep problems in $8 \%$, and post-traumatic stress reactions between 35 to $40 \%$ (Lai et al., 2020; Rossi et al., 2020). The prevalence of anxiety and depression in southern China in a sample of the population where none of their relatives or those around them was infected with coronavirus were $8.3 \%$ and $14.6 \%$, respectively, and the percentage of those who had a person who had been infected with coronavirus in their area rose to $12.9 \%$ and $22.4 \%$. This rate is much higher than the prevalence of anxiety in groups that were not infected, $6.7 \%$, and $11.9 \%$ (Lei, Xiaoming, Shuai \& Jinrong, 2020). In a Chinese study of students isolated for illness, the prevalence of PTSD symptoms was $2.7 \%$ and depression was $9.0 \%$, in addition to anxiety and sleep disorders (Tanga et al., 2020). In a systematic review and meta-analysis conducted based on available databases on the prevalence of stress, anxiety, and depression in the general population during the COVID-19 pandemic in Science Direct, Embase, 
Scopus, PubMed, The Web of Science Databases (ISI), and Google Scholar of 17 studies from Japan, Iran, China, India, Iraq, Nepal, the United Kingdom, Spain, Italy, and Nigeria, concluded that the pressure distribution was $29.6 \%$ (the conclusion was based on five studies in which the sample size was 9074 using the Depression, Anxiety and Stress Scale, DASS-21). The prevalence of anxiety was $31.9 \%$ (based on 17 studies where the number of respondents with a sample size of 63,439), and the prevalence of depression was $33.7 \%$ (based on 14 studies with a sample size of 44,531). The study also found that the highest prevalence of anxiety (32.9) was in Asia, whereas the highest prevalence of stress was in Europe (31.9), with the highest prevalence of depression in Asia (35) (Salari et al., 2020). There are literature reviews dealing with adolescents' mental disorders related to coronavirus due to stressful life events, prolonged home detention, intense sadness, domestic violence, and excessive use of the Internet and social media, which reported that the COVID-19 pandemic may exacerbate mental disorders, such as PTSD, depression, anxiety, and symptoms associated with grief. Adolescents with mental disorders are at risk of disruption or changes in care and management and may experience an increase in symptoms (Guessoum et al., 2020). A Pakistani study (Aqeel, Shuja, Abbas, Rehna \& Ziapour, 2020) of 500 students using the Beck Depression Scale, Beck Anxiety Inventory, Revised Illness Perception Questionnaire, and The Warwick-Edinburgh Mental Well-being Scale for assessing depression, anxiety, illness perception, and mental health disorders found that the prevalence of anxiety was higher than that of depression. The level of mild anxiety reached $20.5 \%$, moderate anxiety was $13.6 \%$, while the level of severe anxiety was $22.7 \%$ and the level of natural anxiety was $43.2 \%$. Regarding depression, it was found that the degree of normal depression was $65.9 \%$, mild depression $9.10 \%$, the average was 9.12 $\%$, and severe anxiety was $15.90 \%$. The multiple regression analysis also concluded that anxiety disorders and depression mediated the relationship between mental health and awareness of the current illness. In Singapore, the prevalence of anxiety was $14.5 \%$, depression was $8.9 \%$ and stress was $6.6 \%$, with a $7.7 \%$ incidence of PTSD. Also, $10 \%$ of non-medical health care workers suffered from anxiety, which is higher than the anxiety levels experienced by medical professionals, whose anxiety rate was $10.8 \%$ (Tan et al., 2020).

It is too early to assess the psychological effects of the coronavirus, however, the available overviews show the variety of mental health problems and disorders resulting from the coronavirus crisis, regardless of whether these problems are directly related to the disease, such as anxiety, symptoms of PTSD, depression, fear of stigma, or whether problems that are not directly related, such as those resulting from the deterioration of the economic situation, staying at home, domestic violence and social isolation between different groups (Turabian, 2020). Nirmita et al. (2020) stated that in their 
survey between March 20 and 30, 2020, for example, the Kaiser Family Foundation found that the proportion of older people who reported the existence of anxiety and stress-related to the coronavirus was $31 \%, 49 \%$ of adults.

The psychosocial characteristics of the coronavirus crisis are similar to those of other crises in general, such as time continuity, risk expectations, difficulty in controlling potential, and predicting outcomes. However, this crisis differs from others in several features including the difficulty of assessing the degree of proximity or distance to the hazard. In some cases, despite the preventive measures in place, it is difficult to avoid infection. Also, there is the fear of inadvertently harming others in the event of illness and the associated feelings of guilt. In addition to viewing the disease as a kind of stigma that in some cases can lead to social isolation and suicide attempts. Besides, we refer to suicide attempts due to the economic conditions resulting from the coronavirus crisis, domestic violence, and alcohol consumption. Foreign nationals in some countries have also suffered from discrimination, which has come in various forms, such as avoidance and bullying in some cases (Goya, Chauhan, Chhikara, Gupta \& Singh, 2020; Gunnell et al., 2020; Mamun \& Griffiths, 2020; Thakur \& Jain, 2020).

\section{The study problem and objectives}

This study is concerned with providing a measure of COVID-19-related PTSD and defining its global components. Providing a suitable measuring instrument is therefore one of the fundamental steps in understanding the nature of the psychopathological reactions to corona and helps in determining the extent to which psychological symptoms are spreading. Based on the above, the objectives of this study were:

- Create a reliable scale for measuring PTSD symptoms

- Exploring the psychometric properties of the questionnaire

- Checking the global structure of the scale through exploratory factor analysis

- Verify the validity of the model using confirmatory factor analysis

\section{The study importance}

The importance of this study is to develop a PTSD symptom scale that can help mental health professionals reliably diagnose people with PTSD symptoms, then help plan psychological support and appropriate interventions.

\section{The limits of the study}

The study limits are determined in the time frame of the implementation between March and June 2000, the extent of the efficiency of the items to cover symptoms of PTSD, the sample characteristics, and the effectiveness of the statistical methods to answer the questions raised. 


\section{Methodology and Procedures}

The descriptive approach was used for its convenience in achieving the study objectives, and in answering questions related to PTSD symptoms and the mental health scale of the Criterion Related Validity examination.

\section{The sample}

The data for the study were obtained through an electronic survey. The sample consisted of 423 respondents from the Sultanate of Oman, undergraduate, graduate and postgraduate students. The mean age of the entire sample was $37.04 \pm 7.48$ years, including 219 men with a mean age of $38.42 \pm$ 8.31 years and 204 women with a mean age of $35.56 \pm 7.02$. None of the respondents stated that they had developed symptoms of the corona at the time of the study.

\section{Corona-related PTSD scale}

The scale was mainly designed based on the Davidson scale (Davidson et al., 1997; Davidson, Tharwani \& Connor, 2002; Meltzer-Brody, Churchill \& Davidson, 1999) and contained 17 items to measure three dimensions: intrusive re-experiencing, avoidance/numbness traumatically experience, and hyperarousal. The scale was used in many studies and had good psychometric indicators, with Cronbach's alpha coefficients above 0.90. These reliability coefficients were extracted from studies on various samples such as Davidson et al. (1997), McDonald, Beckham, Morey, and Calhoun (2009) and MeltzerBrody, Churchill, and Davidson (1999).

In the current study, we adjusted the 17 items to ask about the situation that is specifically related to the coronavirus, for example: "I am having difficulty enjoying my life and doing daily activities that I am used to due to the corona crisis?" Answers were rated on a hex scale from (one to six): all the time, most of the time, a relatively good time, sometimes a little, no time. A high score indicates symptoms of PTSD.

Wie used the Davidson Scale as a guide for formulating new items related to Corona. We have formulated a similar content item structure to make sure the content validity of PTSD symptoms. Accordingly, the developed scale can be viewed as a new instrument, ie not as a mere translation and use of the Davidson scale.

\section{Results}

Scales validity and reliability in its current version.

Face Validity

The modified version of the scale was reviewed by a number of experts in this field to ensure clarity of the Items and the extent to which the scale covered the dimensions of PTSD symptoms. There were no major modifications. 


\section{Internal Consistency}

The average correlation between items: In the first step, the correlations between the 17 items were calculated, with the average correlation matrix between the scale items shown in Table 1.

Table 1: Average Inter-PTSD Correlation Matrix

\begin{tabular}{|c|c|c|c|c|c|c|c|c|c|c|c|c|c|c|c|c|}
\hline & 1 & 2 & 3 & 4 & 5 & 6 & 7 & 8 & 19 & 10 & 11 & 12 & 13 & 14 & 15 & 16 \\
\hline PTSD01 & 1.000 & & & & & & & & & & & & & & & \\
\hline PTSD02 & .440 & 1.000 & & & & & & & & & & & & & & \\
\hline PTSD03 & .602 & .473 & 1.000 & & & & & & & & & & & & & \\
\hline PTSD04 & .510 & .351 & .567 & 1.000 & & & & & & & & & & & & \\
\hline PTSD05 & .199 & .073 & .292 & .437 & 1.000 & & & & & & & & & & & \\
\hline PTSD06 & .112 & .108 & .106 & .222 & .335 & 1.000 & & & & & & & & & & \\
\hline PTSD07 & .427 & .382 & .357 & .305 & .162 & .261 & 1.000 & & & & & & & & & \\
\hline PTSD08 & .401 & .222 & .390 & .437 & .213 & .201 & .389 & 1.000 & & & & & & & & \\
\hline PTSD09 & .401 & .287 & .328 & .309 & .109 & .209 & .452 & .554 & 1.000 & & & & & & & \\
\hline PTSD10 & .397 & .246 & .348 & .325 & .090 & .148 & .397 & .471 & .710 & 1.000 & & & & & & \\
\hline PTSD11 & .377 & .298 & .350 & .276 & .139 & .160 & .329 & .310 & .415 & .468 & 1.000 & & & & & \\
\hline PTSD12 & .319 & .232 & .334 & .363 & .083 & .201 & .414 & .456 & .450 & .520 & .396 & 1.000 & & & & \\
\hline PTSD13 & .401 & .346 & .392 & .443 & .163 & .165 & .486 & .453 & .529 & .568 & .359 & .679 & 1.000 & & & \\
\hline PTSD14 & .416 & .306 & .338 & .363 & .134 & .213 & .507 & .422 & .468 & .516 & .351 & .544 & .671 & 1.000 & & \\
\hline PTSD15 & .434 & .393 & .383 & .336 & .112 & .166 & .495 & .394 & .458 & .488 & .468 & .545 & .587 & .607 & 1.000 & \\
\hline PTSD16 & .437 & .380 & .433 & .396 & .164 & .115 & .480 & .437 & .529 & .566 & .377 & .503 & .665 & .630 & .643 & 1.000 \\
\hline PTSD17 & .498 & .381 & .471 & .447 & .218 & .177 & .464 & .391 & .395 & .440 & .298 & .477 & .564 & .508 & .600 & .640 \\
\hline
\end{tabular}

Table 1 shows that most of the items are related to one another to an acceptable degree, with some items showing weak correlations. The lowest correlation was 0.07 between two items ( 5 and 2), while the highest correlation was 0.67 between two items (12 and 13). Since the scale is based on different dimensions, initially all items were kept in the subsequent analyzes, and the decision whether or not to remain weakly correlated items was based on the results of the exploratory and confirmatory factor analysis. 


\section{Reliability}

The analysis of the item reliability and the corrected overall correlation of the items led to the result shown in Table 2.

Table 2 shows that all Cronbach's alpha coefficients were high for individual items, with the lowest discriminant coefficient for item no. 6 reaching a value of 0.25 , which is an acceptable coefficient. In contrast, the highest Corrected PTSD-Total Correlation for item 16 reached a value of 0.71 . The Cronbach's alpha coefficient for the full scale was 0.91 .

\begin{tabular}{|c|c|c|c|c|c|}
\hline & $\begin{array}{c}\text { Scale } \\
\text { Mean if } \\
\text { PTSD } \\
\text { Deleted }\end{array}$ & $\begin{array}{c}\text { Scale } \\
\text { Variance if } \\
\text { PTSD } \\
\text { Deleted } \\
\end{array}$ & $\begin{array}{c}\text { Corrected } \\
\text { PTSD-Total } \\
\text { Correlation }\end{array}$ & $\begin{array}{c}\text { Squared } \\
\text { Multiple } \\
\text { Correlation } \\
\end{array}$ & $\begin{array}{c}\text { Cronbach's } \\
\text { alpha if PTSD } \\
\text { Deleted }\end{array}$ \\
\hline PTSD01 & 44.6245 & 244.120 & .546 & .465 & .905 \\
\hline PTSD02 & 46.0072 & 255.403 & .434 & .301 & .908 \\
\hline PTSD03 & 45.1017 & 245.832 & .578 & .527 & .904 \\
\hline PTSD04 & 44.5593 & 240.586 & .592 & .541 & .904 \\
\hline PTSD05 & 44.1930 & 250.182 & .373 & .356 & .911 \\
\hline PTSD06 & 44.4987 & 257.321 & .251 & .196 & .914 \\
\hline PTSD07 & 44.8670 & 241.687 & .596 & .406 & .904 \\
\hline PTSD08 & 44.0508 & 243.118 & .568 & .416 & .905 \\
\hline PTSD09 & 44.4622 & 238.953 & .638 & .588 & .902 \\
\hline PTSD10 & 44.6623 & 239.009 & .618 & .551 & .903 \\
\hline PTSD11 & 45.0906 & 239.361 & .615 & .413 & .903 \\
\hline PTSD12 & 44.7640 & 239.082 & 619 & .442 & .903 \\
\hline PTSD13 & 44.6219 & 239.339 & .689 & .574 & .901 \\
\hline PTSD14 & 44.6565 & 239.205 & .684 & .574 & .901 \\
\hline PTSD15 & 45.1591 & 235.879 & .714 & .613 & .900 \\
\hline PTSD16 & 44.8950 & 236.108 & .719 & .638 & .900 \\
\hline PTSD17 & 45.3090 & 240.361 & .663 & .489 & .902 \\
\hline
\end{tabular}

\section{Validity}

\section{Criterion Validity}

The criterion validity was checked by analyzing the correlation coefficient of the PTSD scale with the GENERAL WELL-BEING20 by Heubeck and Neil (2000). The general mental health scale has 20 items that measure two dimensions: mental well-being and mental distress. The analysis showed the presence of a negative correlation coefficient (-0.67) between the total value of the corona-associated PTSD symptom scale and the total value for mental health. There was also a negative correlation with the subdimension "psychological well-being" with a value of -0.54 , while the correlation with the sub-dimension "psychological distress" was positive with a correlation value of 0.70 . 


\section{Exploratory factor analysis}

The seventeen items were subjected to an exploratory analysis to examine the global item structure and check the validity of the theoretical assumption on which the item construction was based, namely the grouping of sporadic symptoms into specific syndromes that correspond to the symptoms described in the specialist references on symptoms of PTSD. Table 3 gives an overview of the rotated factor analysis matrix, its commonality, and the degree of saturation.

Table 3: Rotated Factor Matrix

\begin{tabular}{|c|c|c|c|c|c|}
\hline & \multirow[b]{2}{*}{ Items } & \multicolumn{3}{|c|}{ Factor } & \multirow[b]{2}{*}{ Commonalities } \\
\hline & & 1 & 2 & 3 & \\
\hline 13 & $\begin{array}{l}\text { Because of the corona crisis, I get bouts of tension } \\
\text { and anger. }\end{array}$ & .737 & & & .692 \\
\hline 12 & $\begin{array}{l}\text { Due to the corona crisis, I find it difficult to fall } \\
\text { asleep or my sleep has become restless. }\end{array}$ & .712 & & & .615 \\
\hline 14 & $\begin{array}{l}\text { Due to the COVID19 crisis, I am having trouble } \\
\text { concentrating. }\end{array}$ & .686 & & & .597 \\
\hline 15 & $\begin{array}{l}\text { As a result of this crisis, I feel on the verge of } \\
\text { collapse and it has become easy to get distracted. }\end{array}$ & .683 & & & .649 \\
\hline 16 & $\begin{array}{l}\text { I get nervous and tense for the slightest reason and } \\
\text { have the worst expectations. }\end{array}$ & .641 & & & .520 \\
\hline 17 & $\begin{array}{l}\text { I'm scared, my heart is beating faster, and I'm upset } \\
\text { when people around me talk about COVID19. }\end{array}$ & .592 & $\begin{array}{l}.4 \\
2 \\
7\end{array}$ & & .562 \\
\hline 7 & $\begin{array}{l}\text { I have the feeling that my memory is blurry and that } \\
\text { I am having difficulty remembering familiar things } \\
\text { due to the corona crisis. }\end{array}$ & .470 & & & .395 \\
\hline 3 & $\begin{array}{l}\text { I Often have annoying thoughts that I could be } \\
\text { infected with COVID19. }\end{array}$ & & $\begin{array}{l}.7 \\
5 \\
1\end{array}$ & & .644 \\
\hline 4 & $\begin{array}{l}\text { I get angry about the things that might remind me of } \\
\text { the COVID19 virus. }\end{array}$ & & $\begin{array}{l}.6 \\
5 \\
0\end{array}$ & & .516 \\
\hline 1 & $\begin{array}{l}\text { I have fantasies, memories, and thoughts about the } \\
\text { risk of developing COVID19. }\end{array}$ & & $\begin{array}{l}.6 \\
3 \\
9\end{array}$ & & .550 \\
\hline 2 & $\begin{array}{l}\text { I have bad dreams about getting infected with the } \\
\text { COVID19 virus. }\end{array}$ & & $\begin{array}{l}.4 \\
6 \\
8\end{array}$ & & .312 \\
\hline 5 & $\begin{array}{l}\text { I try to avoid thoughts or feelings that remind me of } \\
\text { the COVID19 virus. }\end{array}$ & & $\begin{array}{l}.4 \\
0 \\
6\end{array}$ & & .168 \\
\hline 9 & $\begin{array}{l}\text { I feel isolated, distancing from people, and I no } \\
\text { longer feel any joy because of the corona crisis. }\end{array}$ & & & $\begin{array}{l}.8 \\
5 \\
3\end{array}$ & .846 \\
\hline 10 & $\begin{array}{l}\text { I have the feeling that my feelings are frozen as a } \\
\text { result of the coro na crisis. }\end{array}$ & .448 & & $\begin{array}{l}.6 \\
4 \\
3\end{array}$ & .639 \\
\hline
\end{tabular}


8 I am having trouble enjoying my life and doing the daily activities that I was used to before the corona crisis? imagine the possibility of staying alive for a long time to achieve my life goals.

6 I avoid following anything (news and information) .067 that may remind me of the COVID19 virus.

The factor analysis was conducted using the method of maximum likelihood and the varimax rotation. Kaiser's criterion was that the variance of the factor or its eigenvalue should be greater than or equal to one. The factor analysis revealed three factors that explained the relatively acceptable percentage of $49.93 \%$ of the total variance of the items. The three factors comprised 15 items out of 17 items. Since the saturation of the remaining two items was lower than the predetermined saturation on the factor $(0.40)$, these items were excluded. The KMO value was 0.92 and Bartlett's test of sphericity was significant (0.00).

Table 3 also shows that almost all factors were saturated with items consistent with each other and expressed homogeneous groups of symptoms that can be divided into PTSD-specific syndromes concerning COVID-19.

The stability factor for the items of each separate factor was calculated again separately. The Cronbach's alpha for the first factor was 0.89 , the corrected total correlation of the items was between 0.58 and 0.77 , the Cronbach's alpha for the second factor was 0.79 and the corrected total correlations of the items were between 0.33 and 0.76 , the Cronbach's alpha for the third factor was 0.77 . The corrected total correlation of the items was between 0.47 and 0.69 .

\section{Confirmatory factor analysis}

The structural validity of the scale was checked using confirmatory factor analysis based on the factors that resulted from the exploratory factor analysis to test the quality of the model fit. This procedure was performed by testing the GFA structural validity model, factor confirmatory analysis, and the compatibility of the AMOS structural model. The exploratory factor analysis yielded 15 items saturated with three factors, which explains $49.93 \%$ of the total variance, and the interpretation ratios were $22.07 \%$ for the first factor, $15.14 \%$ for the second factor, and $12.17 \%$ for the third factor.

Accordingly, the patterns were designed according to these three dimensions. Figure 1 shows the results of the first-order confirmatory analysis in its final form after deleting item 17 due to the high value of the residual covariances, the deletion of which led to an improvement in the model fit. 


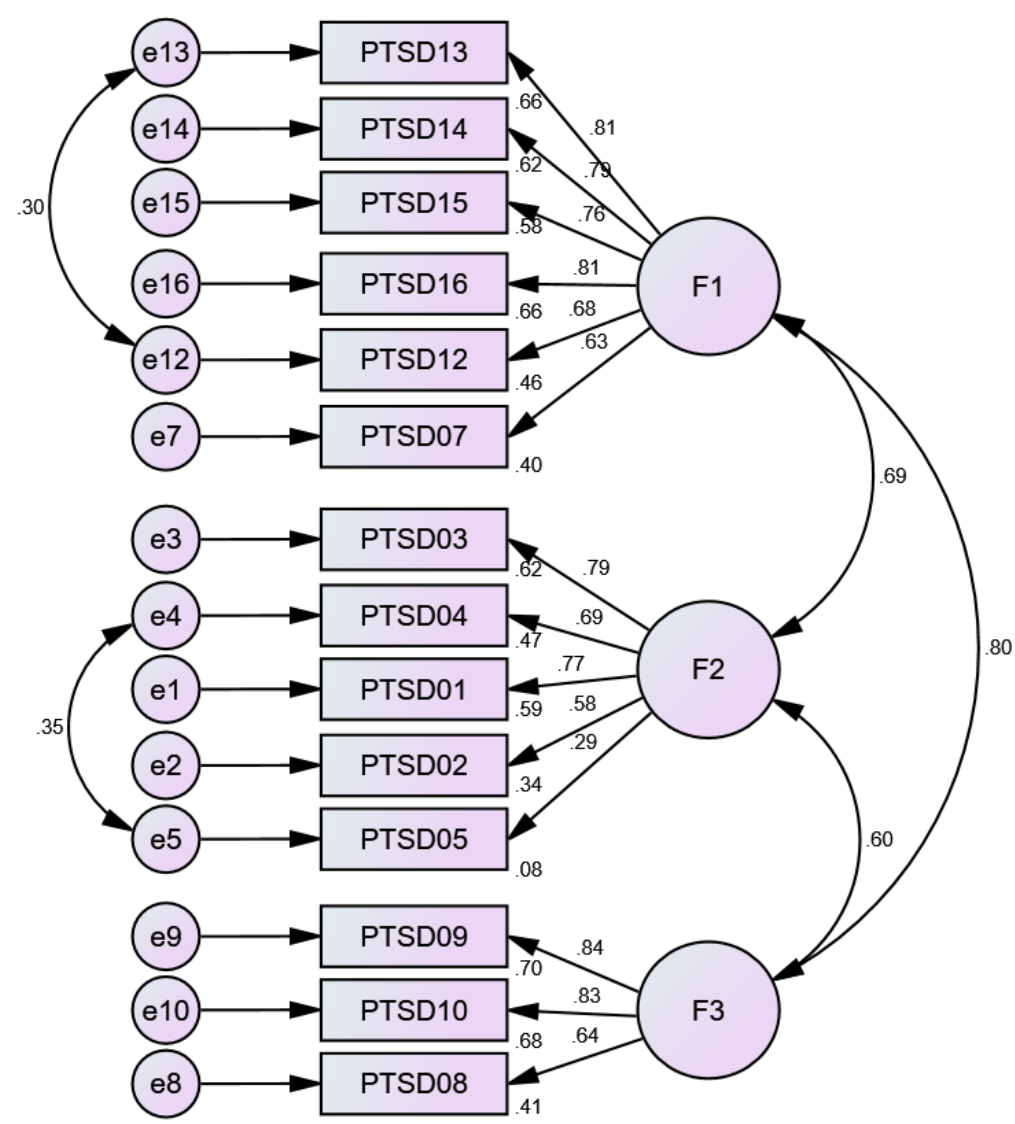

Figure 1 : First-order confirmatory analysis: interpreting the latent variables for correlations between the observed variables 


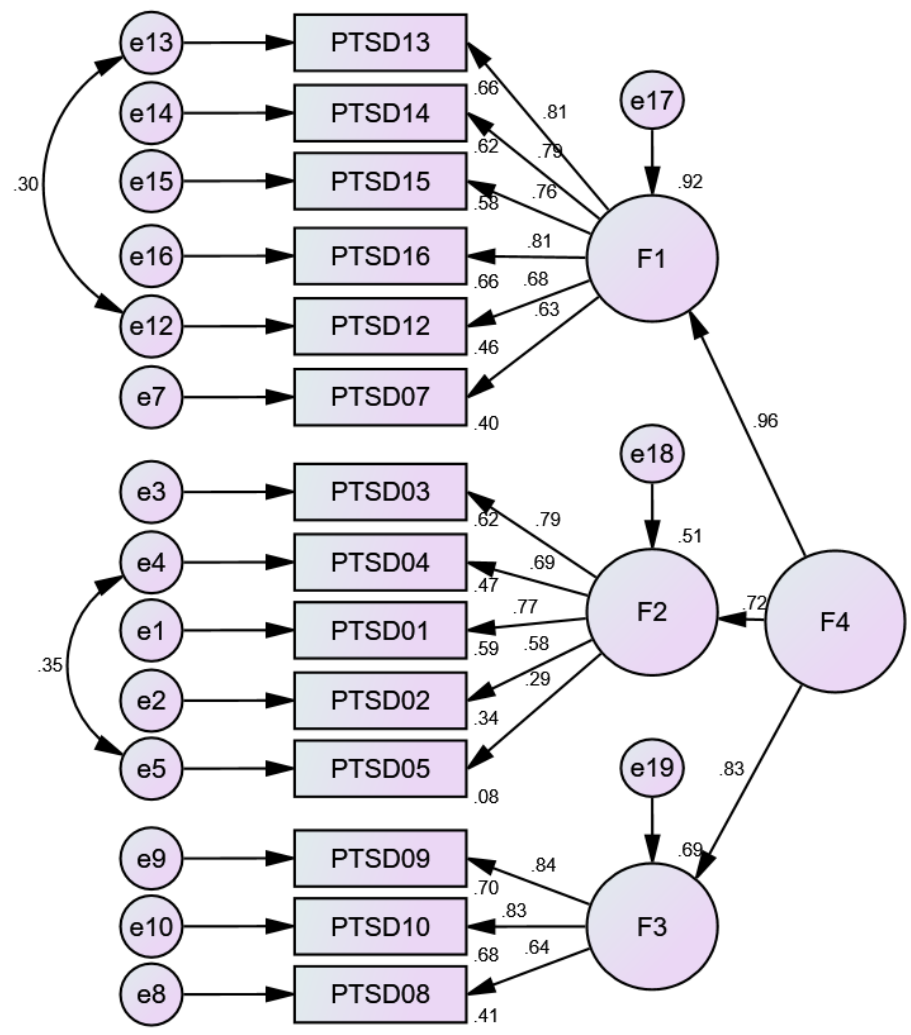

To clarify the quality of the model's indicators, some indicators were presented in Table 4.

Table 4: Indicators of the Goodness-of-Model fit

\begin{tabular}{|c|c|c|}
\hline Indicator & $\begin{array}{l}\text { computed } \\
\text { value }\end{array}$ & $\begin{array}{l}\text { Acceptance } \\
\text { Criteria }\end{array}$ \\
\hline $\begin{array}{l}\text { Chi-Square or } \\
x^{2}\end{array}$ & 184.96 & n.s. \\
\hline $\mathrm{DF}$ & 72 & I \\
\hline $\begin{array}{l}\text { Probability } \\
\text { level }\end{array}$ & 0.000 & \\
\hline CMIN /DF & 2.56 & $\mathrm{x} / \mathrm{df}<5$ \\
\hline \multicolumn{3}{|c|}{ absolute fit index } \\
\hline RMSEA & 0.061 & RMSEA $<0.08$ \\
\hline \multicolumn{3}{|c|}{ Baseline Comparisons } \\
\hline TLI & 0.95 & TLI $>0.90$ \\
\hline
\end{tabular}




\begin{tabular}{lll}
\hline NFI & 0.93 & NFI $>0.90$ \\
CFI & 0.96 & CFI $>0.95$ \\
\hline
\end{tabular}

From Table 4, it can be concluded that the indicators for the goodness of fit were good and that all model estimates showed a function at the 0.01 level. However, it should be noted that the chi-square value was not significant and the CMIN/DF was less than 5. This is a good indicator of the model. The RMSEA index was less than 0.08 and greater than 0.05) Also, all other values met the conditions for the goodness of fit.

\section{Discussion}

This study developed a scale for measuring the symptoms of PTSD related to COVID-19 with good psychometric properties and reliability coefficients suitable for use. The scale was characterized by high stability coefficients. The correlations between the symptoms of PTSD associated with COVID-19 were high with both mental health and the dimensions of psychological well-being and distress.

Factor analysis revealed three factors, reflecting 15 out of 17 elements, which were characterized by a high degree of consistency in their content and agreement with clinical facts, confirming the obvious validity based on which the scale was established. The consistency of the factors with one another was demonstrated by separately calculating the stability coefficients and the correlation of the element with the total degree of the elements of each factor. The overall correlation coefficients for the items were between 0.33 and 0.77 and the stability coefficients were between 0.77 and 0.89 ). Some saturation of the factors suggested that the various symptoms measured were not entirely independent of each other and that other underlying factors need further investigation.

The analysis of the first and second-order confirmation factors led to the validation of the model and concluded that 14 items represent the best model. The indicators for the goodness of fit achieved good values. Nevertheless, further tests with other samples are required, such as infected persons, as well as people who have recovered from the disease and their close relatives. These further studies could provide more evidence for the validity of the scale.

\section{References:}

1. Aqeel, M., Shuja, H. K., Abbas, J., Rehna, T. \& Ziapour, A. (2020). The influence of illness perception, anxiety, and depression disorders on students' mental health during the COVID-19 outbreak in Pakistan: 
A web-based cross-sectional survey. doi: https://doi.org/10.21203/rs.3.rs-30128/v1

2. Davidson, J., Book, S., Colket, J., Tupler, L., Roth, S., David, D. \& Feldman, M. (1997). Assessment of a new self-rating scale for posttraumatic stress disorder. Psychological Medicine, 27(1), pp. 153-160. doi: https://10.1017/s0033291796004229

3. Davidson, J., Tharwani, H. \& Connor, K. (2002). Davidson Trauma Scale (DTS): Normative scores in the general population and effect sizes in placebo-controlled SSRI trials. Depression and Anxiety, 15(2), pp. 75-78. doi: https://10.1002/da.10021

4. Goya, 1. K., Chauhan, P., Chhikara, K., Gupta, P. \& Singh, M. P. (2020). Fear of COVID 2019: First suicidal case in India! Asian Journal of Psychiatry, 101989, pp. 101989. doi: https://doi.org/10.1016/j.ajp.2020.101989

5. Guessoum, S. B., Lachal, J., Radjack, R., Carretie, E., Minassian, S., Benoit, L. \& Moro, M. R. (2020). Psychiatry research. Adolescent psychiatric disorders during the COVID-19 pandemic and lockdown, 291, pp. 113264. doi: https://doi:10.1016/j.psychres.2020.113264

6. Gunnell, D., Appleby, L., Arensman, E., Hawton, K., John, A., Kapur, N. \& Pirkis, J. (2020). Suicide risk and prevention during the COVID19 pandemic. The Lancet Psychiatry, 7(6), pp. 468-471. doi: https://doi.org/10.1016/S2215-0366(20)30171-1

7. Heubeck, B. \& Neil, J. (2000). Confirmatory factor analysis and reliability of the Mental Health Inventory for Australian adolescents. Psychological Reports, 87(2), pp. 431-440. doi: https://DOI:10.2466/PR0.87.6.431-440

8. Lai, J., Ma, S., Wang, Y., Cai, Z., Hu, J., Wei, N. \& Hu, S. (2020). Factors associated with mental health outcomes among health care workers exposed to coronavirus disease in 2019. JAMA network open, 3(3), pp. e203976. doi: https://doi.org/10.1001/jamanetworkopen.2020.3976

9. Lei, L., Xiaoming, H., Shuai, Z. \& Jinrong, Y. (2020). Comparison of the prevalence and associated factors of anxiety and depression among people affected versus people unaffected by quarantine during the COVID-19 epidemic in southwestern China. Med Sci Monit, 26, pp. e924609. doi: https://DOI:10.12659/MSM.924609

10. Mamun, M. A. \& Griffiths, M. (2020). First COVID-19 suicide case in Bangladesh due to fear of COVID-19 and xenophobia: Possible suicide prevention strategies. Asian Journal of Psychiatry, 51, p. 102073. Advance online publication. doi: https://doi.org/10.1016/j.ajp.2020.102073 
11. McDonald, S., Beckham, J., Morey, R.\& Calhoun, P. (2009). The validity and diagnostic efficiency of the Davidson Trauma Scale in military veterans who have served since September 11th, 2001. Journal of Anxiety Disorders, 23(2), pp. 247-255. doi: https://10.1016/j.janxdis.2008.07.007

12. Meltzer-Brody, S., Churchill, E. \& Davidson, J. (1999). Derivation of the SPAN, a brief diagnostic screening test for posttraumatic stress disorder. Psychiatry Research, 88(1), pp. 63-70. doi: https://doi:10.1016/s0165-1781(99)00070-0

13. Nirmita, P., Rabah, K., Kendal, O., Cynthia, C., Rache, G., Liz, H. \& Priya, C. (2020). The Implications of COVID-19 for Mental Health and Substance Use. Retrieved from https://www.kff.org/: https://www.kff.org/report-section/the-implications-of-covid-19-formental-health-and-substance-use-issue-brief/\#endnote_link_4604191

14. Rossi, R., Socc, V., Pacitt, F., Di Lorenzo, G., Di Marco, A., Siracusano, A. \& Rossi, A. (2020). Mental health outcomes among frontline and second-line health care workers during the coronavirus disease 2019 (COVID-19) Pandemic in Italy. JAMA network open, 3(5), pp. e2010185. doi: https://doi.org/10.1001/jamanetworkopen.2020.10185

15. Salari, N., Hosseinian-Far, A., Jalali, R., Vaisi-Raygani, A., Rasoulpoor, S., Mohammadi, M. \& Khaledi-Paveh, B. (2020). Prevalence of stress, anxiety, depression among the general population during the COVID-19 pandemic: a systematic review, and metaanalysis. Globalization and health, 16(1), pp. 57. doi: https://doi.org/10.1186/s12992-020-00589-w

16. Sanwang, W., Win, X., Dong, Y., Bin, L.\& Cui, M. (2020). Psychological Influence of Coronavirus Disease 2019 (COVID-19) Pandemic on the General Public, Medical Workers, and Patients With Mental Disorders and its Countermeasures. doi: https://doi.org/10.1016/j.psym.2020.05.005

17. Tan, B., Chew, N., Lee, G., Mingxue, J., Goh, Y., Yeo, L. \& Sharma, V. (2020). Singapore, Psychological Impact of the COVID-19 Pandemic on Health Care Workers in. doi: https://https://doi.org/10.7326/M20-1083

18. Tanga, W., Huc, T., Hu, B., Jine, C., Wang, G., Xie, C. \& Xu, J. (2020). Prevalence and correlates of PTSD and depressive symptoms one month after the outbreak of the COVID-19 epidemic in a sample of home-quarantined Chinese university students. Journal of Affective Disorders, 274, pp. 1-7. doi: https://doi.org/10.1016/j.jad.2020.05.009 
19. Thakur, V. \& Jain, A. (2020). COVID 2019-suicides: A global psychological pandemic. Brain, Behavior, and Immunity, 88, pp. 952953. doi: https://doi.org/10.1016/j.bbi.2020.04.062

20. Turabian, J. (2020). Implications on mental health by the coronavirus disease 2019 (COVID-19) pandemic: The role of the general practitioner. Arch Psychiatr Ment Health, 4, pp. 035-041. doi: https://doi:10.29328/journal.apmh.1001016 